\title{
CLASSIFICATION OF ARCHAEOLOGICAL SITES FOR HERITAGE MANAGEMENT INVENTORY: THE CASE OF THE ANCIENT SYNAGOGUES IN THE GALILEE
}

\author{
Yael Alef ${ }^{1}$ \\ ${ }^{1}$ Bar-Ilan University, Department of geography and Environment, Ramat Gan, 5290002 Israel; Israel Antiquities Authority, \\ Conservation Department, Nahalal 10600, P.O.B. 35, Israel - yaelalef@ gmail.com
}

\author{
Commission II, WG II/8
}

KEY WORDS: Archaeological Resource Management (ARM), Heritage inventory, GIS, Conservation, Ancient synagogues, Israel

\begin{abstract}
:
A conservation survey of 66 ancient synagogues in the Galilee, served as a pilot for the development of an inventory for heritage management in the Israel Antiquities Authority. The pilot raised some issues concerning the information categories and their informed use for decisions making about the conservation policy for the sites. These issues formed the basis for ongoing research that examined the significance of the information categories and their interrelationship, from the heritage management perspective. The paper presents some of the results and focuses on the classification of the sites to management types. The classification is based on their excavation status with regards to management status and management activities. From this criterion six types emerged: A) Remains known from surveys (Non-excavated); B) Ongoing excavation, and excavated, which are subdivided into four additional groups: C) Remains cleared for modern development (after salvage excavation), D) Non-Stewarded; E) Partially Stewarded; and F) Stewarded. This classification enables to identify common characteristics and sensitivities for which management policy can be formulated, thus providing a solution to the complexity, and dynamism of the sites variables, conditions, and values. While in other fields and organizational frameworks, the types may vary, the criteria for classification, could be applied in broader contexts as well. The study concludes with the need for applied research on the practical use of inventories for informed heritage management.
\end{abstract}

\section{INTRODUCTION}

A conservation survey of ancient synagogues in the Galilee found that while some sites were developed for tourism and are managed with considerable resources, other sites are forgotten, abandoned and destroyed. Who is responsible for this situation? How is Israel's archaeological heritage managed? What information is required and how is it used for management? This question, which is at the center of this paper, is of increasing importance to archaeologists and heritage managers alike. Developments in information technologies are changing practices of Archaeological Resource Management (ARM), and inventories which once were no more than archival lists of sites are becoming information systems for heritage management.

The issue of information for heritage management came about during the survey of the Ancient Synagogues in the Galilee conservation project (Alef, 2015), which led to ongoing research about inventories for heritage management. At the same time, an initiative to establish a national heritage inventory was beginning to develop (Alef, 2017), with the intention that the research will be part of this system's needs analysis and help to characterize the knowledge model in the national inventory.

The subject of inventories is related to the broad issue of ARM that Carman (2015) defines as all the practices of documentation, assessment, conservation, research, and presentation of the remains from the past to the public. In spite of it values, the nonrenewable archaeological resource is exposed to damage from development, looting, inappropriate uses, the destructive nature of the research excavation, along with natural destruction and weathering processes. The main purpose of ARM is to mitigate those risks and balance the conflicting interests of research, development, education, community and the developing tourism industry. Informed decision-making regarding those challenges relays on the information infrastructure of the management system. Therefore, inventories are designed to facilitate identification, classification, and documentation, in order to conserve the assets and integrate them into sustainable research and planning processes. Today, inventories are expected to enable collection, processing, and presentation of data on heritage assets for various purposes such as research, management, public participation, and sharing of knowledge (Bold, 2009). However, the question of the practicality of the inventories and the way they are used in the management process remains.

The Israel Antiquities Authority (IAA) inventory for example, is rarely used by heritage mangers. This inventory includes data about 30,000 declared antiquities sites that has been collected from surveys and archaeological excavations. It consists of information on the type, periods and location of the remains. However, it does not contain data on the physical condition of the remains, and if they still exist after the salvage excavation, as well as any information about their cultural evaluation, thus it is not possible to sort and rank sites for conservation. There is also no information on stakeholders and what ARM activities are in place. The IAA's inventory was designed primarily to manage archaeological research and it fails to respond to the current needs of heritage management.

The paper presents preliminary findings from a research of the information characteristics required in an ARM inventory. It will focuse on a central finding that emerged from the analysis of the information categories, which is a model for classification of archaeological sites from the management perspective and the types that were identified. 


\section{RESEARCH BACKGROUND}

The vital role of inventories in the management of archaeological heritage is recognized and expressed in doctrinal conservation documents, such as the Charter for the Protection and Management of the Archaeological Heritage (ICAHM, 1990) and the European Convention on the Protection of the Archaeological Heritage (Council of Europe, 1992). This recognition also led to the development of an International Core Data Standard for Archaeological Sites and Monuments (Thornes and Bold, 1998; Bold, 2009).

Nonetheless, a critical discussion and specific research on inventories for archaeological management is still in its early stages. This is especially evident in comparison to the extensive discussion of inventories in the context of archaeological research (Carman, 2015). Literature about inventories at large describes how heritage information systems and data standards evolved in different countries and, in some cases, provide an overview of the main components of the system (Carlisle and Lee, 2016; Smuts, Mlungwana, and Wiltshire, 2016; Van Daele, Meganck, and Mortier, 2015; Palumbo, 2004). However, when Myers (2016:104) discusses the challenges in developing the Arches data management platform for the heritage field, he finds "lack of attention focused on defining the key elements of effective heritage inventory programs".

Indeed, little is also said on how the information is used in the heritage management framework and its effectiveness in decision-making, particularly regarding the characteristics of archaeological heritage. That is, research that looks at the information needs for management which goes beyond the documentation of the remains; to include its management status; development for tourism and statutory status in terms of land use and their interrelations. The growing threat to the archaeological heritage and the necessity to develop appropriate management tools to improve its protection, conservation, and development, reinforces the need to explore the characteristics and functions of heritage management systems. Inventories today include numerous sites with many variables along with complex analysis possibilities. The problem that arises from the heritage manager's perspective when referring to an inventory is the array of information categories and variables for a single site or a region. The literature has not yet dealt with the applied research of these tools, such as how and what knowledge the heritage manager produces from the system in the management process: What is the significance of the different information categories and their interrelations? What is the significance of the variables in the various administrative situations for decision-making? What queries can the heritage manager run to derive this knowledge from within the system?

When the time came to formulate a policy and strategy for the conservation of the Galilean synagogues based on the data from the survey, we encountered the same problem described above. Thus, the main research questions emerged: What is the significance of the information characteristics in an inventory for ARM? What are the interrelationships between them, and what are the issues which stem from the analysis of the information regarding heritage management? During the study, another question emerged from the findings of the survey and the analysis of the information categories: Is it possible to identify types of archaeological sites for heritage management needs?

Following these questions, the article will propose an approach to the classification of archaeological assets according to their excavation and management status. These two categories were found significant from the ARM perspective. We will attempt to show that this classification can provide some solution to the complexity of variables and factors in heritage management.

\section{METHODOLOGY}

\subsection{The field}

The research consists of 66 survey records of synagogues from the Roman and Byzantine periods in the Galilee. The survey was limited to the northern region of the country and only includes records of "remains of building" that are identified as synagogues. It does not include over 90 sites where architectural elements characteristic of synagogues were found, but structural remains were not located. (see map in Figure 4).

The ancient synagogues have been a focus of archaeological research in Israel for over a century (Levine, 2000). By the first century $\mathrm{CE}$, the synagogue institution had already assumed an important role in Jewish life with social and cultural functions. After the destruction of the Temple in Jerusalem in $70 \mathrm{CE}$, the synagogue offered a radical alternative and became the first buildings representing monotheistic space where people worshipped without idols. Like other public buildings of the time, it was lavishly decorated with architectural features and mosaics. The largest concentration of synagogue buildings in ancient Palestine is preserved in the Galilee. Early at the beginning of the state of Israel, the synagogues of Bet Alpha, Bar'am and Meron were developed as National Parks. In 2000, the Ancient Synagogues in the Galilee were presented to UNESCO World Heritage Sites tentative list for their Outstanding Universal Value (UNESCO World Heritage Center, 2000).

The synagogues that were surveyed form a well-defined typology of high cultural value and historical, archaeological and geographic characteristics. Nevertheless, the study of this unique case study aims to gain insights beyond the specific typology. Altogether, the sites vary and display a range of conditions. While some have been excavated, conserved and developed as tourist sites, others are not managed, some are neglected and have been destroyed. Some of the sites were discovered in salvage excavations in urban areas, but most of the sites are in open areas designated for agriculture, nature reserves or national parks.

\subsection{Research framework}

Method of analysis: The primary research approach following the research questions about the significant information characteristics of the survey records, is essentially qualitative. Yet, the first stage is a descriptive-quantitative analysis of all the sites according to the characteristics of each category. Hence, the unit of analysis is the survey record in a GIS, of 'building remains' type, that is related to an 'artefact' record, and to 'a ruin' or 'cultural landscape' record. The data was collected during the filed survey done by a team of an architectural conservator (the author), an archaeologist - heritage manager and a conservator, to obtain a comprehensive understanding of the site (Alef, 2015, 2017).

The GIS technology is an ESRI ArcGIS Online 'off the shelf' platform, which was chosen because it is already in use in the IAA. The information categories (entry fields) are based on the Core Data standard (Thornes and Bold, 1998) in the following areas: names and references, location and spatial data, functional type, period, building materials and techniques, physical condition, legal status and historical summary. Significance assessment filed was also included. For the purpose of this paper 
the management status consists of statutory category e.g. local authority, land zoning, designation protection and site management category e.g. visitation statues, managing body and current use. Activities category includes data on surveys and archaeological excavations status and conservation status. In most categories, the values are predefined (selection from a list) and the historical description and evaluation are entered in text.

\section{Stages of the research procedure:}

I. The survey phase: included characterization and construction of a preliminary GIS which was then used for compiling the information from a field survey. During the survey, the characteristics of each category were reformulated.

II. Data analysis: comprised of three levels of the data analysis for each information category in the record: analysis of the synagogue status, analysis of the significance of the category based on the data, and finally, identifying the issues that emerged from the category's significance. The analysis involved:

1. Analysis of each category: by the distribution of all the sites and identification of the interrelation between important management categories.

2. Comprehensive analysis of eight records: by representative sites in different management status. Those served to identify the significant categories of management at each site. The analysis included the formulation of indepth significance assessment, identifying of contexts and information components required in the system, as well as identification of the central issues of management information needs, which arise from cultural evaluation.

3. Sites classification: the analysis generated six site types, based on the main characteristics of information for management in relation to the excavation status. These types are a central finding in this study and are described below.

III. Refining the Issues: The overall analysis extracted the issues of information in heritage management. As the research is ongoing, the future stage will focus on refining these key issues in order to create an overall profile of the information needs in the archaeological heritage management system. The description of this step is not included in the article.

\section{FINDINGS}

\subsection{The role of management and excavation status}

From the data analysis, two categories - the excavation status and the management status - stand out from all the significant categories, and the interrelationships between them, as having the potential to classify the sites. The description of the finding, therefore, is limited to those aspects.

\section{EXCAVATION STATUS}

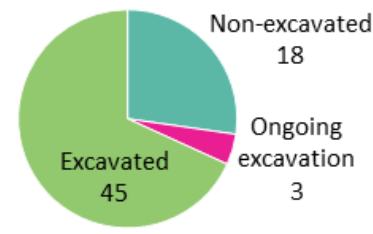

Figure 1. Distribution of sites according to excavation status

The intensive study of synagogues resulted in the excavation of two-thirds of the known synagogues sites in the north and continues today with three new excavations of synagogues (Figure 1). Examining the conservation status of the excavated sites, for example, found that in 2013 about half of the synagogues underwent conservation, while the other half remained exposed to deteriorate. In 2018 , following the national projects for the conservation and presentation of synagogues, the situation improved. Examination of the level of intervention in relation to the development of the remains for visitors found, that most of the treated remains were sites developed for tourism. One-third of the synagogues underwent massive reconstruction, while other sites were not treated at all.

From the perspective of the heritage manager, the meaning of the management status characteristics can also be examined in relation to other categories, such as an examination of the type of custodians, managing the area in relation to ARM activities such as supervision, planning, conservation and development, and maintenance (Figure 2,3). To illustrate the problem of ARM information complexity, we shall describe the interrelation that revealed the following: Three sites in military zones suffer damages induced from improper use of heritage. Among the private custodians, five sites are under ongoing management, three of them in churches and two in archaeological parks. Half of the sites managed by public organizations such as the National Parks undergo ongoing or occasional care, two sites suffer from damage and inappropriate use, and in 12 sites the management status is unknown. In the local authorities, the number of sites suffering from damage and inappropriate use, which in some cases have caused the loss of the remains, is prominent.

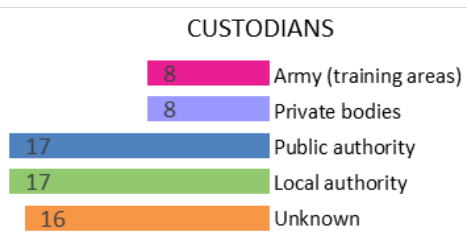

Figure 2. Sites distribution according to the type of custodians

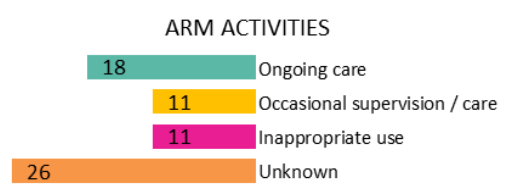

Figure 3. Sites distribution according to the type of activities

The results highlight the number of sites where management status is unknown, which points to the difficulty in locating this information, in part due to lack of awareness among the stakeholders, to the very existence of the archaeological sites in the area. Those results also reflect the ambiguity regarding the need to manage the sites and lack of a clear definition of responsibility for their protection and conservation. The management components, together with the excavation status, formed the primary criteria for classifying the sites according to the management needs as described below.

\begin{tabular}{|c|c|c|c|c|}
\hline Management Type & $\begin{array}{c}\text { Excavation } \\
\text { status }\end{array}$ & Custodians & $\begin{array}{c}\text { ARM } \\
\text { activities }\end{array}$ & $\#$ \\
\hline $\begin{array}{l}\text { A. Remains known from } \\
\text { surveys }\end{array}$ & No & & Non & 18 \\
\hline B. Ongoing excavation & Ongoing & & & 3 \\
\hline Excavated remains & & & & \\
\hline $\begin{array}{l}\text { C. Remains cleared for } \\
\text { development }\end{array}$ & Yes & Non & Non & 3 \\
\hline D. Non-Stewarded & Yes & Yes & Non & 13 \\
\hline E. Partially Stewarded & Yes & Yes & Partial & 13 \\
\hline F. Stewarded & Yes & Yes & Yes & 16 \\
\hline
\end{tabular}

Table 1 . Site classification by management components 


\subsection{Site classification by management components}

The study found assets with common information characteristics, which can be sorted into six types according to ARM needs. The types derived from analysis of the data according to categories in the information system, and from the detailed analysis of eight survey records of representative synagogues. Classification criteria include information from excavation and management status (Table 1). The distribution shown in Table 1. reflects a unique, well-known and high-value theme. Therefore, it is likely to find more 'Stewarded' remains than other types in comparison to other typologies, and on the other hand, less 'Remains cleared for development' type. The distribution of types in other typologies is likely to change, with, for example, greater representation of 'Remains known from surveys' and 'NonStewarded remains. Figure. 4 displays the spatial distribution of the different types.

Type A: Non-excavated remains: This group includes 18 synagogues that were identified in archaeological surveys; they are not excavated and can serve as reserves for the future. The surveys included: $100 \mathrm{sq} \mathrm{km}$ survey map of the Archaeological Survey of Israel such as in H. Gevul, detailed surveys such as in $\mathrm{H}$. Mimlah, and thematic surveys. The quality of the information varies between the sites, but as a rule, it is currently relatively low. The remains are collapsed, mostly buried in the ground and are not prominent in the landscape. in many cases accessibility to the sites is difficult. The synagogues in this group are of cultural value which is mainly granted by their context to the ruin in the archaeological landscape and as part of the typological theme. Many of them, such as H. Gevul and Yahudiyya, yielded important artifacts which are displayed in museums. However, the sites themselves are usually not managed as heritage sites and are not developed for visitors. All in all, there is less awareness of the existence of the sites both among the bodies managing the area and the public.

The remains underground are protected from the environment, but their hidden nature exposes them to risks from agriculture and earthwork. Such damage was induced to an ancient cave in $\mathrm{H}$. Mimlah when the Forestry Administration (KKL-JNF's) opened a new road to the hilltop, at the center of the ruin. In the case of $\mathrm{H}$. Nator looting destroyed much of the site. Because the sites in this group are hidden underground mostly unknown, the definition of the boundaries in the information system is a central issue. Communicating this information to the bodies operating in the area is critical for raising awareness to the site's vulnerability.

Type B: Sites undergoing excavation process: This group includes Huqoq, H. Kur, and H. Majduliya synagogues, which are currently undergoing excavation (as of 2017) that is conducted in an academic framework. The other form is salvage excavations. The phase of the excavation is a crucial junction in the 'life' of the site. The excavation yields new information that changes our understanding of the property and its cultural significance. The site is then 'sentenced' to further research, destruction, conservation and/or tourism development. The excavation in Huqoq, for example, revealed extraordinary mosaics that attracted considerable interest. While the excavation is still underway, plans are already made to develop the site for visitors. This is a temporary and dynamic status that can last several weeks or a few seasons until the site is transferred to the 'excavated' status and finds its place along with other sites in one of the sub types.

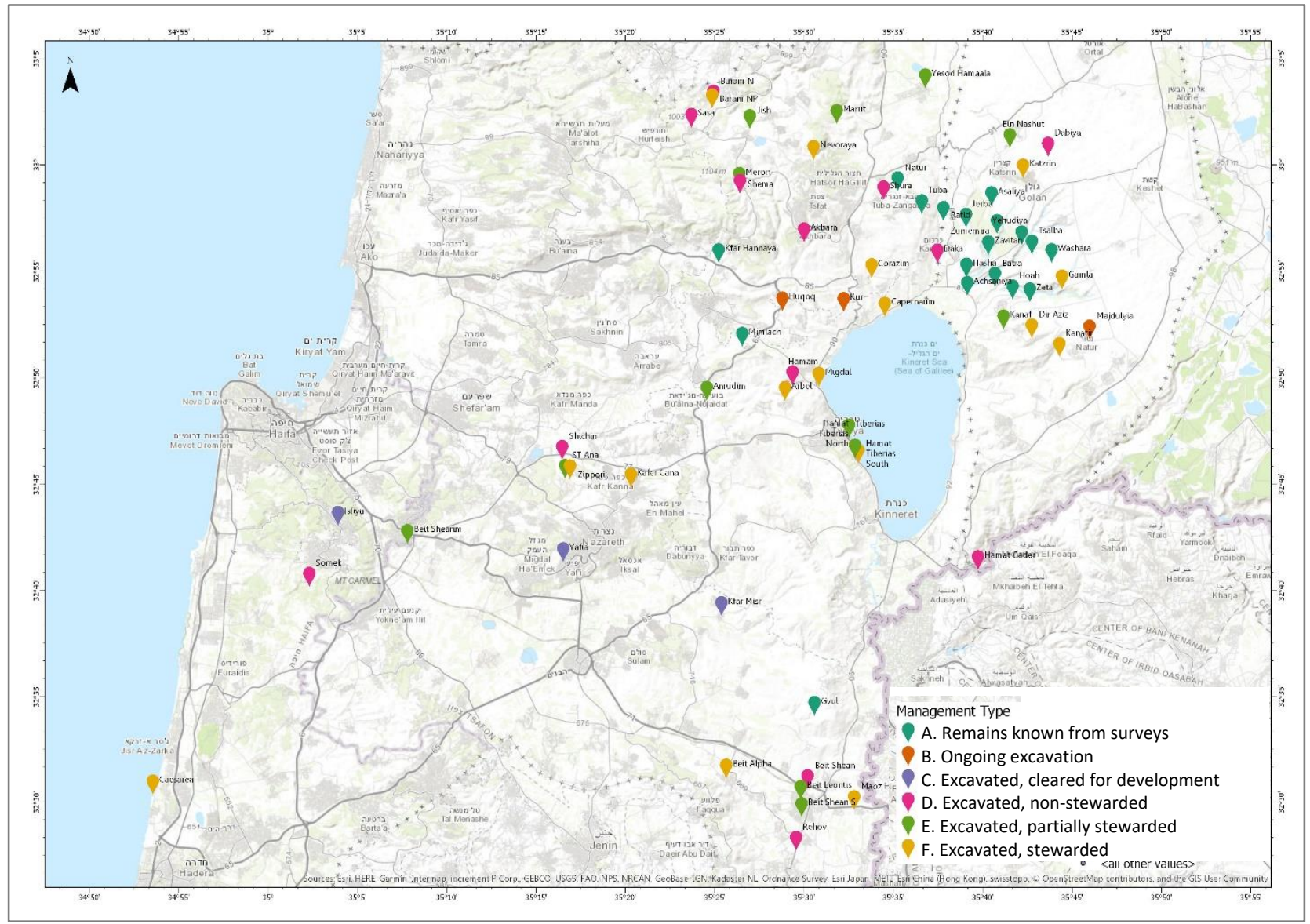

Figure 4. Map of the Synagogues classified by management components 
The group of sites under excavation raises a few issues in the context of the information system. A site in the process of excavation is in a sensitive situation until its future is decided, whether to be permanently reburied or alternatively developed for visitors. The synagogue in Kh. Wadi el-Hammam, whose excavation ended years ago, is an example of this interim situation that has been lingering for years. While efforts are being made to allocate funding for its conservation and development the site is exposed without proper conservation and protection. Thus, in terms of the information needs for management at this stage, timing is of paramount importance.

Type C: Remains cleared for development (after Salvage excavation): This group includes three synagogues: Yafia, Misr, and Isfiya, which were irreversibly damaged by development of residential buildings on the site. To date whatever remained is not perceived and managed as heritage assets. These sites are typically located in urban residential areas, with high development pressures. In Misr, the remains were destroyed immediately upon receipt of the development permit after the salvage excavation. In other cases, such as Yafia, where important mosaics were revealed, there was no deliberate decision to destroy the remains, but after the excavation, the mosaics were lifted for display in the museum. The place was forgotten, and its future abandoned to the point where the actual area was permitted for construction. Both cases resulted in the destruction of the site and the loss of its value as worthy of conservation.

Among the synagogues, this is a small group. When a synagogue is uncovered in salvage excavation, it is not likely that the IAA will allow for clearing of the remains for development due to the importance of the theme. Out of 12 synagogues that were uncovered in salvage excavations, only the synagogue in Misr received a permit for development, and apparently with the intention to remove the remains to be reinstalled elsewhere. The small number of synagogues in this group does not reflect the common practice of massive legal destruction of remains, where salvage excavations are the main challenge for ARM. This problem has two aspects: one concerns the information required in the system to minimize destruction from development by optimizing the integration of sites in planning. The second relates to the documentation of the lost property in the information system. Those records accumulate in the system and eventually expand our understanding of the archaeological context.

Type D: Non-Stewarded remains: This group includes 13 synagogues that were excavated in academic or salvage excavations and were found to be of high value and worthy of conservation. Some of them, such as Hammat Gader, Rehov (H. Parve), and Bet She'an, T. Iztabba (Figure 5), are among the most important synagogues discovered in Israel. In some cases, mosaics and unique artifacts were discovered and lifted for display in museums. In other cases, mosaics were reburied insitu. After the excavation the sites were forgotten. The remains have not been treated, developed for visitors, or managed. Over the years, the sites remained exposed to weathering and damage from inappropriate uses and looting, they deteriorated and are in dangerous conditions. Concluding his extensive research on synagogues 30 years ago, Zvi Ilan (1991:19) warned that "The condition of the excavated synagogues is generally not good. Neglected sites are being destroyed, and their future care will sometimes require renewed excavations and numerous reconstructions after their original remains will be destroyed and withered."
Ilan's warning is still relevant and reflects the management status of the sites. Although half of the assets in this group are under the custody of the Israel Nature and Parks Authority, no ARM activities are being conducted. This group is characterized by a lack of awareness of the high importance of the sites and their inherent potential. This could be explained by the fact that some of the sites, such as H. Shura, are not prominent in the landscape, but others, such as H. Sumaq, H. Shema' and Kh. Wadi elHammam were preserved to a considerable height yet still they are 'invisible sites.' Unlike salvage excavations where a conscious decision is made to destroy the remains, in these sites there is no deliberate decision, but the unique items have been removed, the place has been forgotten, and its future abandoned. These sites can be named 'Invisible Sites' after the famous words of the Little Prince': what is essential is invisible to the eye."

One of the issues that arise from those 'invisible sites' is the separation of the artifacts from the site. Artifacts and mosaics are essential for understanding the site's significance and its potential for development, but in many cases, they have been removed. We find that those sites such as Hammat Gader and Rehov (H. Parve) are in a worse condition than sites where the mosaics are in-situ. The sites supervision and the Archaeological Collections of National Treasures are under two separate departments in the IAA with separate information systems. Thus, there is a need to connect the information systems and re-connect the artifacts to the sites to reconstruct the wealth of meanings and interpretations.

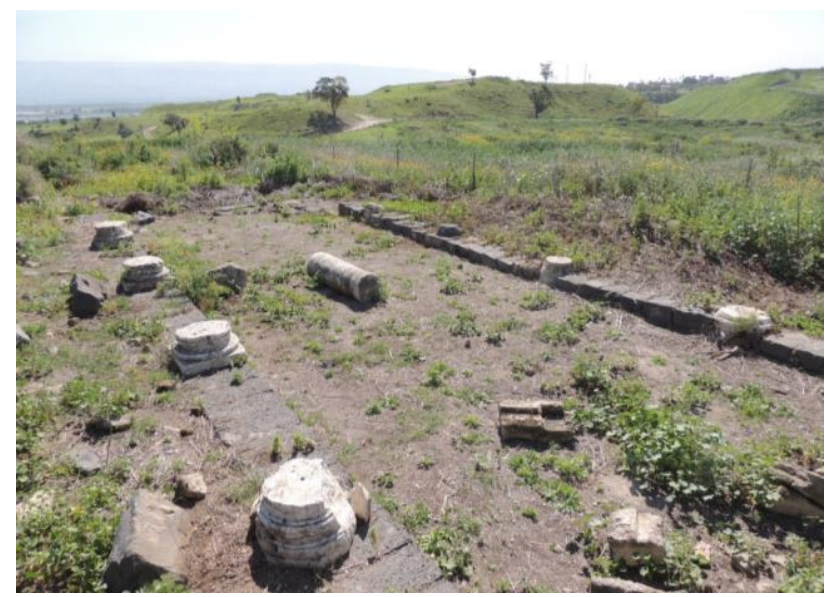

Figure 5. Bet She'an, Tel Iztabba synagogue, type D. (Photo: Y. Alef, 2017 ( IAA)

Type E: Partially Stewarded remains: This group includes 13 high-value excavated synagogues whose management status is unclear. Usually, there is some custodian responsible for the area, for example, a nature reserve under the National Parks Authority which may occasionally undertake maintenance operations such as in H. Merot and Meron (Figure 6). However, there is no ongoing heritage management of the site. The group also includes sites such as Bet Shean South that were discovered in salvage excavations in urban areas. There, unique artifacts were removed, the remains were reburied, and the area is managed by the municipality as a garden. In some of the sites in open areas like H. Ein Nashut and H. Kanaf, the regional authority cleared a path and posted explanation signs. As part of the conservation project of the synagogues in the Galilee, conservation work was carried out in four sites in this group. Other sites were not preserved and remained exposed to environmental threats. Except for the reburied sites, most of the sites in this group are impressive in the landscape, and although unique artifacts were removed, they could potentially be developed for visitors. 
A central issue in this group concerns the management status associated with the multiple bodies involved in managing the area, along with a lack of a clear definition of the responsibility for preserving the archaeological assets in these areas. For example, $\mathrm{H}$. Merot is declared an antiquities site, located in an army training zone within a nature reserve in the Upper Galilee Regional Council. In practice, the main custodian is a group of volunteers - "Friends in the footsteps of Zvi Ilan" - the sites' archaeologists, which arranged for a sign and seating area and occasionally clean vegetation growth in the synagogue. Decisions regarding the protection, conservation, development or destruction of remains are made by various bodies, including tourism entities, which have different authority and interests in areas with archaeological remains. What information and mechanisms are required in the system to enable cooperation between the various stakeholders to promote heritage conservation?

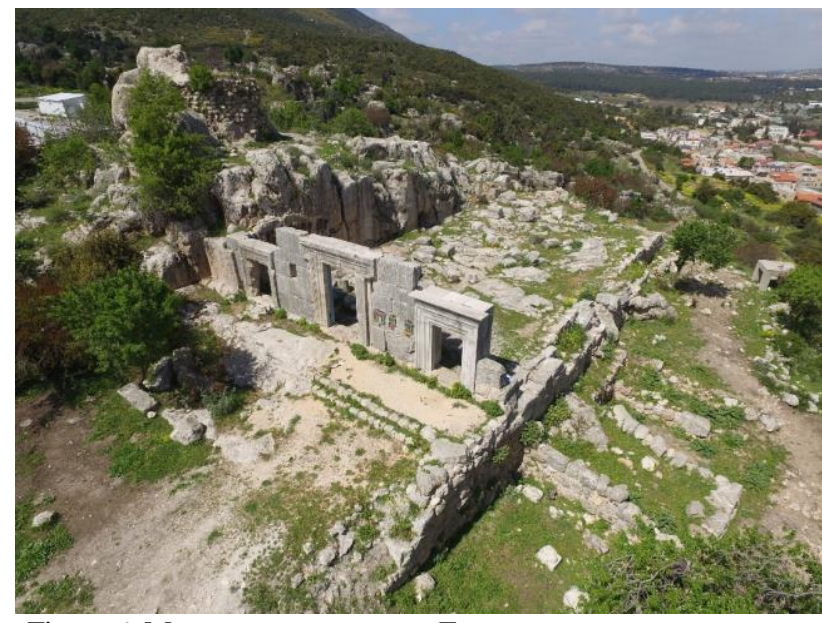

Figure 6. Meron synagogue, type E. (Photo: G. Pitusi, 2016 @ IAA)

Type F: Stewarded properties: This group includes 16 highvalue excavated synagogues that are managed directly under a custodian with authority in the area that cares for their conservation and development. These are tourist sites, such as Qasrin, Dir Aziz (Figure 7), Capernaum, and the national parks of Korazim, Hammat Tiberias and Kh. Beit Alfa. Information about custodians and about their activities is available. These sites have undergone conservation and reconstruction as part of their presentation to the public.

The issues of this group relate to the close link between intervention for conservation and tourism development. Thus, the initiation and funding for conservation are only done as part of a tourism project, while those that are not developed for tourism are not preserved. Several sites that were treated with minimal intervention in the conservation project of synagogues in the Galilee are exceptions. Moreover, the level of intervention in tourism sites is usually intensive and includes large-scale reconstruction as well as new constructions. As a result, in some sites, the authenticity of the archaeological remains has been impaired, and they risk false interpretation such as in the synagogue of Caesarea. The level of intervention of stewarded sites is in no comparison to the other types. There is either no intervention at all or intensive intervention and no balance between the number of resources allocated to a few sites versus the needs of all sites. Also, the initiative to develop the sites for visitors is localized. Decisions on conservation and development of the site derive from tourism considerations that are not represented in the ARM information. Therefore, the question is how to link this information, including characteristics of the display and the data on the resources in the system, in order to support decision-making in a broad view of all the heritage needs in the region?

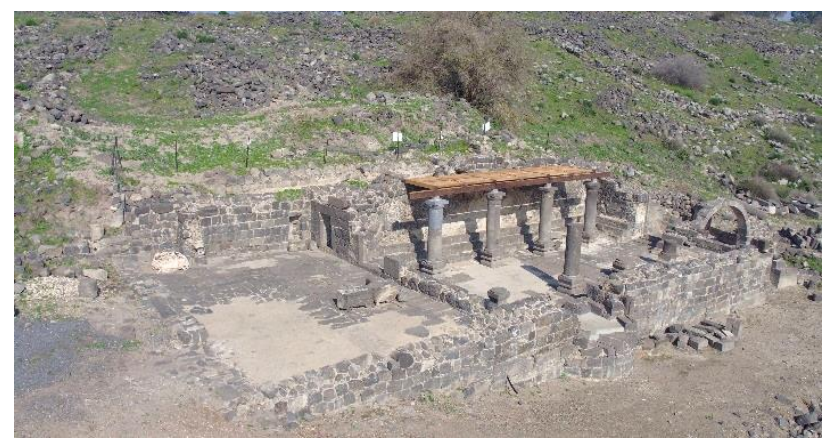

Figure 7. Dir Aziz synagogue, type F. (Photo: M. Peleg, 2018 @ IAA)

\section{DISCUSSION}

\subsection{The classification regarding the information complexity}

The research studies the issue of the significance of the information characteristics in the ARM inventory. When heritage managers use the information system to generate decisionmaking knowledge, they need to compile a lot of data from different fields. Each site has its unique management needs derived from its unique characteristics. This problem poses a challenge when formulating a conservation policy for various sites in a regional or national perspective, for example, the conservation of synagogues in the Galilee. The literature on ARM inventories does not offer ways of linking the information in the system on the specific site or region, to a repertoire of management tools that will meet the needs of heritage conservation.

A certain response to this is possible through the classification of sites in the system according to the status of the excavation and the management status. The proposed classification differs from the common classification to archaeological types that is prevalent in the research, or the classification of properties for legal protection and risks that is common in ARM which stem from the characteristics of the site itself. Up to date information systems such as Arches that intend to be used as a management tool (Carlisle et al., 2014) could integrate management-type classification, along with typologies, risk assessment, and legal status to assist in translating information into decision-making knowledge. Classification according to management needs can help organize information from various aspects that are often found in different systems.

\subsection{Implications of the type properties on decision-making}

The proposed classification enabled to identify common management needs for each type. For each group and its particular sensitivities, a common standard response could be fitted from a repertoire of options. Hence, it is possible to formulate a comprehensive policy for managing sites. The unexcavated sites, for example, are characterized by remains buried underground and are therefore susceptible to damage from agricultural cultivation. Addressing this problem could be by raising awareness of the bodies operating in the area to the existence of the sites and their vulnerability. This is also related to the difficulty to define boundaries of sites of this type. In contrast to the architectural heritage that stands above the ground, the delineation of the boundaries of archaeological remains is a challenging task by the very hidden nature of the resource. In this 
type, in particular, special effort is required to define the boundaries and to represent them in the information system in order to protect the remains.

Sites undergoing excavation process are in a temporary status, and therefore in terms of management information needs at this stage, "timing" of the information in the system is critical. In other words, the entry of updated information for timely management decisions followed by documentation and execution of the decisions, e.g., reburial or destruction of the site for development in salvage excavations or development of the site for tourism. One can also think of a system that will provide alerts such need for an update of cultural assessment in the completion of the excavation.

In sites of high value such as the synagogues theme, where development was permitted, the documentation in the information system is paramount. After the excavation, the property will be demolished. The information about the sites, which is all that would be left, is essential for understanding the broad context. The documentation is also the basis for monitoring the exploitation of the archaeological resource and assigning archaeological reserves from a local and national perspective, according to themes and periods. Assets in this group suffering from sustained damage may have an adequate response by removing the remaining artifacts to prevent further loss of information about the site or even a complementary salvage excavation before the last remnant is gone.

The Non-Stewarded Remains group represents a management failure, where lack of decision on the future of the place and neglect leads to ongoing damage to the site. A prominent characteristic of the sites is the separation between the sites and the artifacts, which in many cases gave the asset its unique value. The link between removing the artifacts and the state of the site requires a comprehensive view, e.g., by connecting the collections in storage or display to their location on the site. In other words, to represent the ontological relationship between the artifact and the site for the various users, heritage managers, researchers, and the public.

This issue could be related to the development of mobile technologies that enable ubiquitous access to information about the sites and artifacts that are not on site, particularly while visiting the site. The technologies allow re-examination of the potential of sites for development, especially 'invisible sites 'such as Rehov, Hammat Gader, and Bet Shea'n, Tel Iztabba, where impressive mosaics where discovered and then removed to museums exhibitions.

Sites belonging to the Partially Stewarded group raise the problem of the multiplicity of bodies involved in managing areas with archaeological sites and the need for cooperation between them. To a certain extent, these sites are also 'invisible.' They could potentially be developed while alternatively, they may deteriorate into a non-stewarded type.

The Stewarded sites are characterized by intensive development and large resource allocation for conservation, in comparison to other sites in the region. However, the initiation and development of the sites is usually local and miss an overall balanced view of the regional or national needs. Intensive intervention level for presentation purposes in these sites is common. In this context, it can be suggested that as part of the development of the site for presentation, some resources would serve to represent the relevant information of the site in the system.
The proposed classification considers the excavation status that is part of the documentation of the remains at the site, together with the management status that includes two variables: who manages the area and what type of ARM activities are conducted on the site. These variables are not part of the documentation of the remains. The classification represents the relationship between categories that derive from the management needs associated with the site's documentation and other management categories. It shows that this interrelation can generate significant information for decision-making. Relationships may also be found between the management characteristics and the risk assessment or the cultural evaluation. However, from the comprehensive analysis of all the categories and their interrelationships, coupled with in-depth analysis of eight records, this study found that the excavation status and management status categories enable valid classification of sites for overall management purposes.

\section{CONCLUSIONS}

The paper presented preliminary findings and conclusions from research on the characteristics of the information required in an ARM inventory. The paper offers an approach to categorize archaeological sites according to their excavation status in relation to their management status, i.e., from the management perspective. The criteria of excavation status and management status stood out as significant categories in the information system. They enable to classify the sites and relate the common management needs of the type, to a repertoire of management tools for the establishment of informed policy adapted to the nature of the group.

The classification for heritage management reflects the interrelation between the categories and enables a holistic perception of the site. Rather than addressing a specific isolated aspect of the management needs of a site, the classification brings about interrelated aspects and enables a systematic perception of management needs. At the same time, it allows for a whole perspective of a region or theme. The classification of groups with common characteristics draws the broad picture required to formulate policies according to specific types while managing all the resources.

The proposed approach classifies archaeological sites into six types as follows: classification into three main groups according to the excavation status: A) Remains known from surveys (not excavated); B) ongoing excavation; and four additional groups of excavated sites, which are subdivided by management status to C) Remains cleared for development (after Salvage excavation); D) Non-Stewarded remains; E) Partially Stewarded remains; and F) Stewarded remains

The proposed classification emerged in the context of the Synagogues Survey, which is a distinct typology of high cultural value that is acknowledged by the administrative system in Israel. However, in other contexts, different types might be found, depending on the nature of the assets, the management framework, different typologies, cultural values or variables related to regions and countries. The vital principle is the very concept of classification according to the excavation status and the management status that can be applied in many instances and further afield.

Further research of ARM inventories, information characteristics and their interrelations, aims to refine the main issues that arise from the information analysis, especially regarding the representation of the necessary connections related to formulating the significance evaluation. Those connections could 
be between the artifact and the asset or spatial representation of the asset as part of its expanding cultural contexts. Refining the issues will enable to define the significant information profile for heritage management that can contribute to the characterization of the information system.

The classification of the sites reflects the change in trend in heritage management information systems from inventory to a management tool and change of emphasis from the documentation of the assets to information about management needs. This trend requires future research on the use of information systems as a management tool. That is applied research on the practical use of information systems and their impact on decision-making processes in heritage management. The insights from actual use will contribute both to the research and to the practice of ARM.

\section{ACKNOWLEDGMENT}

The research is conducted as part of a $\mathrm{PhD}$ dissertation supervised by Prof. Irit Amit-Cohen. In addition, I want to thank Yuval Shafriri for his ongoing support and advice.

\section{REFERENCES}

Alef, Y., 2017. Towards an Inventory for Archaeological Heritage Management in Israel. 26th International CIPA Symposium 2017, 28 August-01 September 2017, Ottawa, Canada, 21-25. https://doi.org/10.5194/isprs-archives-XLII-2W5-21-2017

Alef, Yael, \& Rosenblum, A., 2015. Saving the Synagogues in the Galilee: Conservation from a Regional Perspective. http://www.iaa-

conservation.org.il/Projects_Item_eng.asp?subject_id=10\&site_ $\mathrm{id}=72 \& \mathrm{id}=162$

Bold, J., 2009. Guidance on inventory and documentation of the cultural heritage. Edited by Bold John. Strasbourg: Council of Europe.

Carlisle, P. K. et al., 2014. The Arches Heritage Inventory and Management System: a standards-based approach to the management of cultural heritage information, International Committee for Documentation of the International Council of Museums (CIDOC) Conference: Access and Understanding Networking in the Digital Era.

Carlisle, P. and Lee, E., 2016. Recording the past: heritage inventories in England, Journal of Cultural Heritage Management and Sustainable Development. Edited by D. Myers and Mario Santana Quintero. Emerald Group Publishing Limited, 6(2), pp. 128-137. doi: 10.1108/JCHMSD-02-20160013.

Carman, J., 2015. Archaeological Resource Management. Cambridge: Cambridge University Press. doi: 10.1017/CBO9781139020473.

Council of Europe, 1992. European Convention on The Protection of The Archaeological Heritage (Revised). https://rm.coe.int/168007bd25

ICAHM, 1990. Charter for the Protection and Management of the Archaeological Heritage, Lausanne. ICOMOS. pp. 1-5. doi: 10.1007/978-1-4419-0465-2_1036.
Ilan, Z., 1991. Ancient synagogues in Israel. Tel Aviv (Hebrew).

Levine, L., 2000. The ancient synagogue: The first thousand years. Yale University Press.

Myers, D., 2016. Heritage inventories: promoting effectiveness as a vital tool for sustainable heritage management, Journal of Cultural Heritage Management and Sustainable Development. Edited by D. Myers and Mario Santana Quintero. Emerald Group Publishing Limited, 6(2), pp. 102-112. doi: 10.1108/JCHMSD-02-2016-0009.

Palumbo, G., 2004. Twenty-Five Years of Archaeological Site Inventories in the Middle East, pp. 20-31. http://cot.pennpress.org/media/5306/sampleart3.pdf.

Smuts, K., Mlungwana, N. and Wiltshire, N., 2016. SAHRIS: South Africa's integrated, web-based heritage management system, Journal of Cultural Heritage Management and Sustainable Development. Edited by D. Myers and Mario Santana Quintero. Emerald Group Publishing Limited, 6(2), pp. 138-152. doi: 10.1108/JCHMSD-01-2016-0002.

Thornes, R. and Bold, J. 1998. Documenting the Cultural Heritage. The J. Paul Getty Trust.

http://archives.icom.museum/objectid/heritage/index.html

Van Daele, K., Meganck, L. and Mortier, S., 2015. Data driven systems and system driven data: the story of the Flanders heritage inventory (1995-2015), ISPRS Annals of the Photogrammetry, Remote Sensing and Spatial Information Sciences, II-5/W3(September), pp. 323-327. doi: 10.5194/isprsannals-II-5-W3-323-2015. 